\title{
An Overview of Noninvasive Ventilation in Cystic Fibrosis
}

\author{
AESHA JOBANPUTRA ${ }^{1}$, Sugeet Jagpal ${ }^{1}$, Paula Marulanda ${ }^{1}$, MAYA RAMAGOPAL ${ }^{1}$, \\ TEODORO SANTIAGO ${ }^{1}$, and Sreelatha Naik ${ }^{2}$ \\ ${ }^{1}$ Rutgers Robert Wood Johnson Medical School \\ ${ }^{2}$ Geisinger Wyoming Valley Medical Center
}

June 20, 2021

\begin{abstract}
Noninvasive ventilation (NIV) use was initially reported in cystic fibrosis (CF) in 1991 as a bridge to lung transplantation, and over the decades the use of NIV has increased in the CF population. Individuals with $\mathrm{CF}$ are prone to various physiologic changes as lung function worsens, and they may benefit from NIV for advanced lung disease. As life expectancy in CF has been increasing due to advances such as highly effective modulator therapy, people with CF are now subject to the same comorbidities that may benefit from NIV as their age matched cohorts. NIV can improve gas exchange, quality of sleep, exercise tolerance and augment airway clearance in $\mathrm{CF}$, and it is important that CF providers are comfortable with this therapeutic modality. In this review, we will summarize the physiologic basis for NIV use in CF, describe indications for initiation of NIV, and postulate a practical approach for CF clinicians to take fin monitoring patients on NIV. We will discuss aspects unique to people with CF and the use of NIV. We hope that this serves as a resource for CF providers, especially those of us who do not have dedicated training in sleep medicine, as we continue to care for our patient population.
\end{abstract}

Title: An Overview of Noninvasive Ventilation in Cystic Fibrosis

Authors: Aesha Jobanputra $\mathrm{MD}^{1}$, Sugeet Jagpal MD${ }^{1}$, Paula Marulanda RT ${ }^{1}$, Maya Ramagopal $\mathrm{MD}^{2}$, Teodoro Santiago ${ }^{1}$, Sreelatha Naik $\mathrm{MD}^{3}$

1. Division of Pulmonary, Critical Care and Sleep Medicine, Rutgers the State University of New Jersey, New Brunswick, NJ

2. Division of Pediatric Pulmonary Medicine and Cystic Fibrosis Center, Robert Wood Johnson University Hospital, New Brunswick, NJ

3. Division of Pulmonary, Critical Care and Sleep Medicine, Geisinger Wyoming Valley Medical Center, Wilkes-Barre, PA

Corresponding Author: Sreelatha Naik MD

Email Address:snaik1@geisinger.edu

Address: Geisinger Wyoming Valley Medical Center

1000 East Mountain Blvd. VMB, $1^{\text {st }}$ Floor; Pulmonary Medicine Wilkes-Barre, PA 18711

Disclosures: The authors have no relevant disclosures.Funding: noneKeywords: noninvasive ventilation, sleep apnea, cystic fibrosis, hypercarbic respiratory failureAbbreviated Title: Noninvasive ventilation in Cystic Fibrosis

\section{Introduction}

Noninvasive ventilation (NIV) use was initially reported in cystic fibrosis (CF) in 1991 as a bridge to lung transplantation, and since then, the knowledge base for earlier NIV support of chronic respiratory failure in 
CF has grown. ${ }^{1-3}$ Given the ability of NIV to reverse or stabilize hypoxia, reduce hypercapnia and reduce respiratory muscle fatigue, it is not surprising that many $\mathrm{CF}$ providers have reached for this intervention in patients with advanced lung disease. Concomitantly, it is evident from PortCF registry data that NIV use is increasing over the years despite consistent improvements in lung function attributed to the introduction of highly effective modulator therapy, indicating that NIV is being prescribed to patients without advanced lung disease as well. ${ }^{1,4}$ The PortCF registry currently simply asks if NIV was used by the patient in the past year, but does not ask for the diagnosis that prompted the use, so we are unable to currently report which diagnoses outside of advanced lung disease are prompting NIV use in CF patients.

In the last few decades, epidemiologic trends have demonstrated that improvements in home mechanical ventilation technology and widespread initiation of chronic NIV has resulted in improved clinical outcomes regardless of disease severity in obstructive lung disease. ${ }^{2}$ NIV is often utilized in the acute setting of CF exacerbations, as it improves hypoxia and decreases work of breathing. ${ }^{5}$ In $\mathrm{CF}$ with chronic hypercapnic respiratory failure, use of nocturnal NIV improves sleep related hypoventilation as compared to oxygen use alone. ${ }^{6,7}$ In the earliest study of long-term NIV use in bronchiectasis in 1994, no reduction in hospitalizations was demonstrated, but this was disproven as more research was done and reduction in hospitalizations has been noted in subsequent studies. ${ }^{8}$ In addition, there is increasing evidence that NIV use may augment airway clearance in $\mathrm{CF}^{2}$ and improve survivorship in hypoxic patients when compared to oxygen alone. ${ }^{9}$

In a 2018 survey done by Franco et al, 68 CF centers responded to questions related to sleep. Respondents reported that guidelines regarding sleep testing would be valuable, indicated frustrations with current approved indications for NIV, reported varying levels of comfort with prescribing therapies for sleep disturbance, and stated that educational resources regarding sleep and CF would be well received. ${ }^{10}$

It is clear that NIV use will have a place as an adjunct for CF care itself as well as to treat comorbidities that CF patients develop with continued improvements in lifespan. Therefore, it is important for CF providers to understand the role of this therapy and prescribe it when indicated for patients with CF. In this review, we will describe the role of NIV in the CF population, benefits and risks to this modality, and introduce a practical approach to initiation of NIV. We will also review clinical indications for NIV other than CF in order to provide a better perspective for NIV use.

\section{Physiology of Respiratory Failure In CF}

Nocturnal hypoventilation occurs prior to daytime respiratory failure in CF due to several factors. Firstly, there is increased in work of breathing from reduced respiratory function during sleep combined with altered respiratory mechanics during sleep that act to limit minute ventilation. ${ }^{11,12}$ While, a decrease in minute ventilation would normally elevate $\mathrm{CO}_{2}$ tension, the ventilatory response to $\mathrm{CO}_{2}$ is decreased during sleep, making this compensatory response weak and allowing for hypercapnia. ${ }^{13}$ Finally, there is the influence of the sleep state itself. During REM sleep, inhibition of spinal motor neurons causes atonia of most skeletal muscles. Although the diaphragm is spared from paralysis in REM sleep, accessory muscles of respiration, such as the chest wall muscles that are needed by patients with lung disease to maintain normal ventilation, are paralyzed. ${ }^{14}$ Consequently, hypoventilation is first seen in REM sleep.

In 2002, thirty two CF patients with FEV1 $<50 \%$ were extensively monitored for respiratory physiologic changes longitudinally as disease progression occurred. ${ }^{12} \mathrm{~A}$ key clinical finding in this study was an alteration of breathing pattern to more rapid shallow breathing as pulmonary disease progressed, as well as an observed increased load on respiratory muscles and a decrease in dynamic compliance during resting breathing. ${ }^{12}$ There was little change in the resistive work of breathing, pointing against bronchospasm as the main cause for the increased load. ${ }^{12}$ Hart et al speculated that the declining FEV1 in these patients was due to increased inflammatory changes and destruction of lung parenchyma itself, resulting in reduced elasticity and compliance, increasing the load. ${ }^{12}$ Rapid shallow breathing combined with the increased respiratory load has been demonstrated to contribute to inefficient clearance of carbon dioxide, further contributing to hypoventilation and subsequent hypoxia. ${ }^{15}$ As physiologic changes leading to hypoventilation begin in sleep, intervention at this early point of the cascade of hypoventilation may be helpful in preventing progression. ${ }^{11}$ 
NIV is a treatment modality that could be helpful in preventing the pathophysiology in CF, primarily by maintaining ventilation during sleep.

\section{Benefits of NIV for CF patients}

The use of NIV in patients with respiratory failure in CF has been shown to improve physiologic parameters throughout both sleep and wake states. NIV increases tidal volumes, reduces respiratory rate and reduces respiratory muscle fatigue. ${ }^{1,12,16}$ It may prevent sleep-induced hypoxia even without modification of sleep quality and efficiency, and improves alveolar ventilation during all sleep states. ${ }^{6}$ Even short-term treatment with NIV, such as with 40-minute periods, there are notable acute improvements overall in tidal volume, minute ventilation, and improved oxygenation in patients with respiratory failure from CF. ${ }^{17}$

NIV used only nocturnally improves clinical outcomes including improved hypoxia and hypercapnia at rest, improved sleep quality, and increased respiratory muscle strength. ${ }^{12,16}$ Improved dyspnea, decreased hypoxemia and decreased hypercapnia during exertion and increased exercise tolerance are also seen in patients using NIV nocturnally, potentially allowing patients to take part in the exercise regimens prescribed by their CF care team. ${ }^{18,19}$ NIV also supported recovery from a severe respiratory exacerbation that resulted in hypercapnia. ${ }^{20}$ Long term treatment with nocturnal NIV also minimizes the longitudinal decline in lung function $^{21,22}$ and prevents progression of respiratory failure. These findings have led to the consideration of the use of nocturnal NIV in patients with frequent exacerbations or in those exhibiting a decline in lung function. ${ }^{23}$ Significantly, a prospective randomized controlled trial showed improved survivorship in those treated with long-term nocturnal NIV over those treated with nocturnal oxygen alone. ${ }^{9}$

NIV has also been postulated to improve airway clearance ${ }^{24}$ and has been recommended by recent guidelines in airway clearance for CF patients. ${ }^{25}$ Patients with cystic fibrosis are dependent on airway clearance therapies, and NIV can potentially augment airway clearance. ${ }^{24,26}$ The use of NIV allows a patient to increase functional residual capacity (FRC) with greater ease than a positive expiratory pressure (PEP) device, improving compliance and decreasing work of breathing. ${ }^{27}$ In this same study, chest physiotherapy combined with NIV or CPAP was by patient report less tiring than mask positive expiratory pressure (PEP) therapy. ${ }^{27}$ During NIV treatment, a patient maintains a constant positive airway pressure with the goal to decrease inspiratory work, reduce respiratory rate, increase tidal volumes, improve oxygenation and decrease hypercapnia. ${ }^{26}$ In a study on adult CF patients looking at the addition of NIV for airway clearance, there was a significant reduction in ventilatory inhomogeneity as measured by lung clearance index (LCI). ${ }^{26}$ This indirectly demonstrates less inflammation and mucus plugging in the patients with additive NIV treatment. ${ }^{26}$ Importantly, this finding can be replicated in patients with acute exacerbations, and the addition of NIV during chest physiotherapy also preserves inspiratory muscle strength and improves expiratory muscle strength. ${ }^{24}$

Standford et al looked at a one-year period following the addition of NIV to airway clearance techniques (ACT) and demonstrated statistically significant improvements in ease of patient report of airway clearance and reduced effort during ACT. ${ }^{28}$ This study analyzed objective measures such as lung function and frequency of use of IV antibiotics, as well as patient reported measures of fatigue and breathlessness. ${ }^{28}$ Patients reported significant improvement in fatigue and breathlessness, which would lead to improved quality of life. ${ }^{28}$

Given the high preexisting treatment burden in CF patients, patient reported benefit is important in helping decide best therapies and help with adherence. ${ }^{28}$ It is encouraging that there is both a physiologic benefit to NIV use as well as studies documenting patient perceived efficacy. The definitive benefit in augmenting airway clearance is worth noting for all $\mathrm{CF}$ clinicians.

\section{Risks of NIV in CF Patients}

NIV is well-tolerated by most patients, but it is important to be aware of potential harms of NIV use. ${ }^{29}$ ATS guidelines have listed several contraindications to NIV including inability to protect the airway and effectively clear respiratory secretions. ${ }^{30}$ Guidelines suggest proceeding with caution when considering NIV in patients with extensive gastric distention, ileus, nausea or vomiting, and GERD. ${ }^{29,31,32}$ GERD is one of the most common gastrointestinal manifestations of CF. ${ }^{33}$ It is interesting to note that CFTR modulators are not only 
improving lung function in CF patients, but are also credited with the observed decline in GERD. ${ }^{34}$ Another gastric consequence of using NIV is gastric insufflation, which can compress the lungs, decreasing compliance and increasing mean airway pressures. ${ }^{35}$ This combination of events can lead to increased aspiration, and may contribute to the $5 \%$ increase in aspiration pneumonia seen in NIV patients. ${ }^{29}$ Care should be taken to reduce the risk of gastric consequences including aspiration by timing use of NIV away from mealtimes and having the head of bed raised when possible. ${ }^{36}$ Timing the use of NIV can also allow for breaks for the patient to effectively clear airway secretions.

Barotrauma has also been described in obstructive lung diseases, which includes CF, in the setting of NIV use. ${ }^{37}$ Known steps to minimize barotrauma include using pressure control ventilation in patients with low lung compliance, keeping peak inspiratory pressure as low as possible, avoiding auto-PEEP, and preventing patient-ventilator asynchrony. ${ }^{29}$ Using settings to minimize barotrauma and monitoring for barotrauma is essential when using NIV in obstructive lung disease.

Special precautions also need to be taken with NIV to prevent hemodynamic consequences in patients with chronic right ventricular dysfunction and lung hyperinflation from obstructive lung disease. ${ }^{29}$ Both careful use of PEEP and cautious delivery of low tidal volumes can help mitigate these adverse events. ${ }^{38}$ With the advanced lung disease guidelines suggesting monitoring for hypercapnia and cardiac function in CF patients as lung function declines, it will be easier for $\mathrm{CF}$ clinicians to also consider these data prior to initiation of NIV. ${ }^{39}$

\section{Special Considerations}

\section{CF Exacerbations and Hospitalizations}

A prospective randomized controlled study evaluated comprehensive in-patient care to the same care with the addition of NIV during airway clearance treatments during in-patient admissions for CF exacerbation in patients with moderate to severe disease. ${ }^{40}$ This study reported that the lung function (FEV1) was higher at discharge in the NIV group relative to the usual care group. ${ }^{40}$ It should be noted that the average daily NIV use in the intervention group was only a total of 95 minutes, but still resulted in a measurable difference in lung function. ${ }^{40}$ As described earlier, use of NIV to augment chest physiotherapy has been shown to improve inspiratory and expiratory muscle strength, time with oxygen saturation less than $90 \%$ during sleep, and daytime dyspnea. ${ }^{24}$ Both of these studies support use of NIV for airway clearance during inpatient care, and noninvasive ventilation may have a role for ventilatory support as well. Understandably, no randomized controlled trials of NIV for hypercapnia in CF exacerbations have been performed. In an observational study showed that among 16 ICU patients with severe CF respiratory exacerbation who had NIV prescribed in an effort to avoid invasive mechanical ventilation, NIV was successful in preventing invasive ventilation in $50 \%$ of those patients. ${ }^{41}$ In patients with emphysema, a better studied obstructive lung disease, NIV use during acute exacerbations with suspected hypercapnia has been proven to improve length of stay, reduce need for intubation and reduce in-hospital mortality. ${ }^{42}$

In a survey of hospitals in France, the most common indication for NIV use in CF was hypercapnia greater than $45 \mathrm{mmHg}$ during an acute exacerbation. ${ }^{43}$ Survey results demonstrated that FEV1 and hypercapnia during sleep were not factors for initiating NIV, and NIV was not continued outside the setting of an exacerbation. ${ }^{43}$ However, there is some data to support that hypercapnia during exacerbations may persistent after resolution of exacerbation. ${ }^{44}$ In a study of $19 \mathrm{CF}$ patients admitted for acute exacerbation, $26.3 \%$ of patients $(\mathrm{n}=5)$ had $\mathrm{PaCO}_{2}$ greater than $50 \mathrm{mmHg} .{ }^{44}$ In this hypercapnic group of patients, median $\mathrm{PaCO}_{2}$ was $58.5 \mathrm{mmHg}$ on admission, decreased to $51.7 \mathrm{mmHg}$ on day 7 , and $46 \mathrm{mmHg}$ at treatment completion, which was still not normal. ${ }^{44}$ Median $\mathrm{CO}_{2}$ at day 45 on out-patient arterial blood gas was still $46.7 \mathrm{mmHg}$ in the individuals with hypercapnic respiratory failure. ${ }^{44}$ This small study demonstrates that hypercapnia during in-patient admissions may predict moderate persistent hypercapnia even after discharge, suggesting some value to chronic nocturnal use of NIV post the immediate exacerbation. ${ }^{44}$

Advanced CF Lung Disease 
Hypercapnia is a feature of advanced CF lung disease (ACFLD) as it is among the factors associated with increased mortality in $\mathrm{CF}$, particularly when $\mathrm{PaCO}_{2}$ is greater than $45 \mathrm{mmHg}{ }^{45}$ In a study of 10 patients with severe $\mathrm{CF}$ who had a lung transplant, the baseline $\mathrm{PaCO}_{2}$ was $63.75 \mathrm{mmHg}$ and FEV1 was $15.4 \%{ }^{46}$ Utilization of nasal noninvasive ventilation for 6-8 hours per night reduced the $\mathrm{PaCO} 2$ to 56.25 $\mathrm{mmHg}$ at 3 months and $48.00 \mathrm{mmHg}$ at 6 months. ${ }^{46}$ In this small study, 4 patients died, 3 were transplanted and 3 remained on NIV at the end of the study. ${ }^{46}$ A larger retrospective study of 47 patients with severe CF with hypercapnia also showed that NIV reduced $\mathrm{PaCO}_{2}$ from $50 \mathrm{mmHg}$ at initiation of NIV to 45.9 $\mathrm{mmHg}$ at 1 year, $45.0 \mathrm{mmHg}$ at 2 years and $49.6 \mathrm{mmHg}$ at 3 years. ${ }^{22}$ In addition, in this cohort, while FEV1 fell by $212 \mathrm{~mL}$ in the year prior to NIV initiation, it rose by $18 \mathrm{~mL}$ after 1 year and by $43 \mathrm{~mL}$ at 3 years after NIV Initiation. ${ }^{22}$ Median time on NIV prior to death or transplantation was 16 months with NIV. ${ }^{22}$ In summary, the impact of NIV is impactful across all spectrum of CF disease from mild nocturnal hypoventilation to more severe disease with daytime hypercapnia.

\section{Indications for NIV}

Use of home NIV in chronic respiratory failure is associated with improved survivorship ${ }^{47,48}$, reduced hospitalizations ${ }^{47}$, and improved quality of life. ${ }^{48,49}$ While these benefits were initially noted among patients with neuromuscular disorders, use has expanded other etiologies of hypoventilation, including CF. ${ }^{49}$

NIV has been used in acute and chronic respiratory failure in CF patients. ${ }^{50}$ CF Foundation Consensus Guidelines from 2020 recommend that individuals with advanced CF lung disease (ACFLD) are screened annually for hypercapnia to determine need for home NIV. ${ }^{39}$ NIV was suggested for those with: $\mathrm{paCO}_{2}$ [?] $55 \mathrm{mmHg}$ or $\mathrm{paCO}_{2} 50-54 \mathrm{mmHg}$ and nocturnal hypoxemia, or $\mathrm{paCO}_{2} 50-54 \mathrm{mmHg}$ and more than two hospitalizations in the previous year for hypercapnic respiratory failure. ${ }^{39}$

One of the most common indications for use of positive airway pressure (PAP) therapy is obstructive sleep apnea (OSA). Continuous positive airway pressure (CPAP) therapy was first described to be therapeutic in treatment of OSA back in 1980 s. ${ }^{51}$ PAP continues to be the most effective therapy in decreasing the severity OSA based on objective measurements such as apnea-hypopnea index (AHI) and nadir oxygen desaturations. ${ }^{52}$ However, CPAP may not be effective in treatment of certain OSA populations, such as those who require higher therapeutic pressures or develop treatment-emergent central sleep apnea or complex sleep apnea. ${ }^{53}$ This patient population may require management with NIV such as bilevel positive airway pressure (BPAP) or adaptive servo ventilation (ASV). ${ }^{53,54}$

NIV has also been used for management of treatment-emergent central sleep apnea, central sleep apnea related to other medical conditions such as heart failure or high altitude, central apnea related to medication or substance use, or primary central sleep apnea. ${ }^{55}$ Often these disorders are characterized by presence or absence of hypercapnia $\left(\mathrm{paCO}_{2}\right.$ [?] $\left.45 \mathrm{mmHg}\right) \cdot{ }^{56}$ Primary central sleep apnea, nocturnal hypoventilation associated with neuromuscular disease or underlying lung disease often present with elevated $\mathrm{paCO}_{2} \cdot{ }^{56}$ Meanwhile, treatment-emergent apnea, central sleep apnea associated with heart failure or high altitude, and central apnea associated medication and substance use may present with normal paCO2 levels. ${ }^{56}$ First line treatment for management of central sleep apnea related to heart failure and medication or substance use to optimize the underlying medical condition and discontinue the offending agent if feasible, respectively. ${ }^{57}$ If despite the intervention, central or complex sleep apnea continues, different types NIV can be utilized depending on the underlying condition. ${ }^{56}$

Obesity hypoventilation syndrome (OHS) is another well-known indication for NIV use. OHS is defined by hypoventilation during wakefulness $\left(\mathrm{paCO}_{2}>45 \mathrm{mmHg}\right.$ ), presence of obesity (BMI $>30 \mathrm{~kg} / \mathrm{m}^{2}$ ), and absence of other conditions that may lead to hypoventilation such as underlying lung disease, pulmonary vascular disease, chest wall disorder, medication use, neuromuscular disease, congenital or idiopathic central alveolar hypoventilation syndrome. ${ }^{55}$ Of note, $80 \%$ - $90 \%$ of patients with OHS have comorbid OSA. ${ }^{55}$ Patients with concurrent severe OSA may respond with CPAP treatment alone. However, those without concomitant OSA and primarily nocturnal hypoventilation, defined by $\mathrm{PaCO} 2>55 \mathrm{mmHg}$ for $>10$ minutes or an increase in $\mathrm{PaCO}_{2}>10 \mathrm{mmHg}$ when awake $\mathrm{PaCO} 2>50 \mathrm{mmHg}$ for $>10$ minutes, may require treatment with NIV. ${ }^{56}$ 
In addition, neuromuscular diseases such as amyotrophic lateral sclerosis (ALS), muscular dystrophies, myopathies, and spinal muscular atrophies are also indications for the use of NIV. In fact, use of NIV in ALS patients have demonstrated survival advantage. ${ }^{48,58-60}$ It has been demonstrated that NIV improves outcomes in those with predominantly limb-onset ALS compared to those with primarily bulbar symptoms. ${ }^{60,61}$ Several studies show positive impact on quality of life in these patients with improvement in energy, vitality, shortness of breath, daytime somnolence, depression, concentration, sleep quality, and physical fatigue. ${ }^{48,62-64}$ Although there are no robust data to determine when to initiate NIV in ALS patients, the occurrence of orthopnea, sniff nasal pressure $<40 \mathrm{~cm} \mathrm{H}_{2} \mathrm{O}$, maximal inspiratory pressure $<-60 \mathrm{~cm} \mathrm{H}_{2} \mathrm{O}$, abnormal nocturnal oximetry, or vital capacity $<50 \%$ predicted have been suggested. ${ }^{65}$ In other neuromuscular disorders, NIV initiation has been recommended with the development of nocturnal hypoventilation. ${ }^{66-68}$

In summary, the major indications for the use of NIV include advanced obstructive lung diseases such as $\mathrm{COPD}$ and $\mathrm{CF}$, central sleep apnea, obesity hypoventilation syndrome, and neuromuscular disorders. Figure 1 summarizes the requirements for the approval of home NIV by major insurance carriers.

\section{Types of Noninvasive Ventilators and Masks}

Various types of ventilators are used in a hospital setting and an outpatient setting. Invasive ventilators that are used in the intensive care units (ICUs) are connected to an endotracheal or tracheostomy tube. These ventilators traditionally have separate inspiratory and expiratory limbs, which prevent a patient from rebreathing exhaled air and allow for measurements of inspiratory pressures and exhaled minute ventilation. ${ }^{69}$ Meanwhile, the noninvasive ventilators (NIV) used in the outpatient setting are often smaller and only have single limb with an exhalation port. However, more recently, these distinctions are starting to blur. For example, ResMed Astral 150 and Philips Trilogy Evo, now also have dual-limb circuits available.

The simplest form of noninvasive ventilation, utilized in both the in-patient and home setting, is bilevel positive pressure ventilation (BPAP), which typically has inspiratory positive airway pressure (IPAP) and expiratory positive airway pressure (EPAP) settings. ${ }^{69}$ The difference between the IPAP and EPAP is the amount pressure support that is delivered and will dictate the tidal volumes a patient gets depending on the compliance of their lung-chest wall unit. ${ }^{69}$ There are two different modes on this type of device: spontaneous or spontaneous/timed. ${ }^{69}$ With the spontaneous mode, each breath is patient triggered, whereas with the spontaneous/timed mode, breaths can be patient triggered but a ventilator breath is also delivered at a specific time interval. ${ }^{69}$ Spontaneous/timed mode allows the device to provide a rate (back up rate) when patient is unable to initiate a breath and is a form of pressure control ventilation. ${ }^{69}$

Even more sophisticated ventilators, utilized both in the in-patient and home setting, have advanced modes capable of adjusting inspiratory pressures to target tidal volume. One example of such ventilator mode would be volume assured pressure support (VAPS) where the minimum and maximum pressure support (minPS and maxPS, respectively) is set with minimum and maximum expiratory positive airway pressure (minEPAP and maxEPAP, respectively) to assure that the patient receives the targeted tidal volumes. ${ }^{69}$ The pressures are automatically adjusted to assure the target volume is delivered to the patient. ${ }^{69}$ Volume control is another advanced mode of ventilation that is infrequently used and is reserved mainly for mouthpiece ventilation. ${ }^{69}$

Advantages and disadvantages of these modes are discussed in Table 1 below. However, it should be noted that most studies evaluating use of NIV in CF have utilized some form of BPAP with or without backup rate (Table 2). Further studies are needed to determine the efficacy of VAPS NIV in hypercapnic CF.

It is also very important to assure that the patients are well fitted and comfortable with the mask that they are prescribed. Choosing a mask should be a joint decision between the provider and the patient. Studies have reported that one of best predictor of PAP adherence is early usage. ${ }^{70,71}$ Mask selection and comfort can have significant impact on the early experience and usage. ${ }^{65}$ Therefore, it is vital that patients are allowed to participate in choosing the right mask for themselves. There are a variety of different masks available in different styles and sizes. Some of the nasal mask interfaces in include nasal pillow, with nasal prongs that are placed inside the nose, and a nasal mask, which covers the entire nose. ${ }^{69}$ There are also oronasal masks, which cover the entire nose and mouth, and hybrid masks which cover the mouth, but lie below the nostrils 
without fully covering the nose. ${ }^{69}$ In addition, there is a total face mask, which fits over the entire face. ${ }^{69}$ There are advantages and disadvantages to each type of mask. For instance, the nasal masks are associated with decreased risk for aspiration, aerophagia, and have reported to be more comfortable. ${ }^{69,72}$ Meanwhile, masks with oral interfaces are better at controlling air-leak through the mouth. ${ }^{69,72}$ It is important to spend time trialing and selecting a mask to patient's satisfaction as studies have demonstrated that patients who are well-adapted to their initial mask have better adherence than those that need to exchange masks. ${ }^{73}$ A multidisciplinary CF team, with the appropriate education, is uniquely poised to help with the unique aspects of promoting adherence to NIV.

\section{Initiating NIV}

In initiating home NIV for in chronic hypercapnic respiratory failure CF, important considerations are: 1) when to initiate NIV, 2) what device or settings to choose, and 3) how to initiate NIV. Indications for initiating NIV are described above, specifically as described in the CF Foundation Guidelines for Advanced CF Lung Disease, as well as other comorbidities patients may have such as OSA, OHS, and neuromuscular weakness. For patients with COPD, current CMS reimbursement guidelines for E0470 devices (BPAP) suggest NIV in patients with $\mathrm{paCO}_{2}$ [?] $52 \mathrm{mmHg}$ with time with oxygen saturation [?] $88 \%$ for [?] 5 minutes on 2 LPM oxygen or the patient's daytime flow (whichever is higher), with documentation of clinical exclusion of obstructive sleep apnea. ${ }^{74}$ BPAP ST devices (E0471) may be obtained if $\mathrm{paCO}_{2}$ remains [?] 52 $\mathrm{mmHg}$ and time with oxygen saturation [?] $88 \%$ for [?]5 minutes on bilevel S device with 2 LPM oxygen on the patient's daytime flow (whichever is higher). ${ }^{74}$ No CMS guidelines are currently present for guidance in obtaining more advanced devices.

Table 1 describes common modes of noninvasive ventilation, and Table 2 summarizes studies that observed use of home NIV in CF patients, modes and settings utilized. BPAP S and BPAP S/T were most frequently used. One study by Fauroux et al evaluated the role of backup rate while in pressure support mode (similar to BPAP) or volume control mode, both without end-expiratory pressure. ${ }^{75}$ In this study, back up rates served to reduce respiratory effort and tachypnea, surrogates of degree of respiratory rest. ${ }^{12}$ No randomized controlled trials have evaluated the efficacy of novel modes of NIV such as volume assured pressure support (VAPS) in hypercapnic CF patients. A meta-analysis in hypercapnic COPD showed that VAPS was not superior to pressure support mode in improving $\mathrm{pH}, \mathrm{PaCO} 2$ or oxygenation. ${ }^{76}$

\section{Practical Considerations for Ordering NIV}

When ordering NIV, it is important to provide all the needed documentation to avoid insurance denial or delay in set up. Appropriate records include office or hospital notes, supporting diagnostic and laboratory tests as well as a prescription that includes settings, supplies, diagnosis and length of need as well as demographic information. When choosing a durable medical equipment (DME) provider, it is important to consider if the patient has other medical equipment such as a nebulizer or oxygen. Choosing the same provider for NIV may avoid conflict when NIV needs to be used in combination with oxygen. Also, choosing a DME in network with the patient's health insurance will minimize out of pocket expenses for the patient. Having one DME provider also streamlines things for a patient, much in the same way as having the same specialty pharmacy for CF medications.

BPAP S or ST may be the mode chosen to initiate therapy both in the in-patient setting and for home NIV. Traditionally, in an in-patient setting, NIV is adjusted to target work of breathing, $\mathrm{pH}$ or $\mathrm{paCO}_{2} \cdot{ }^{77}$ For patients with hypercapnic COPD, the American Thoracic Society recommends normalization of awake arterial $\mathrm{CO}_{2}$ tension. ${ }^{78}$ While similar treatment goals have not been established in hypercapnic $\mathrm{CF}$, it is recommended that NIV be initiated for elevated $\mathrm{CO}_{2}$ tension. ${ }^{39}$ Establishing a goal of reducing awake $\mathrm{paCO}_{2}$ to approach eucapnia may be a reasonable goal. ${ }^{77}$ In addition to evaluation of arterial blood gases, review of data from NIV may be helpful to determine if treatment targets are met. Common targets in NIV learned from other disease states are ensuring that sufficient tidal volumes are being delivered, and that there is sufficient ventilatory rest. ${ }^{79,80}$

Cloud systems monitoring home NIV use can provide data on usage, average leak, residual apnea-hypopnea 
index (AHI), pressures used, tidal volumes, and respiratory rate. Diagnostic and adherence reports can be accessed by creating an account atwww.airview.resmed.com andwww.careorchastrator.comfor ResMed and Respironics, respectively. The patient demographics and equipment information is uploaded by the DME company and linked to the provider's account.

In some patients, NIV can worsen work of breathing and these patients must be identified rapidly in order to seek guidance from sleep boarded physicians ${ }^{77}$. It is important that CF providers review any downloads that cause concern with an expert in this field. A download report can be first looked at for hours of compliance nightly, followed by checking for leaks, then assessing tidal volumes, and finally for residual AHI. Residual respiratory events, patient ventilator asynchrony and upper airway obstructive events negatively impact patient-related outcomes, health related quality of life, and survival ${ }^{81}$. It is important that NIV be systematically monitored by the CF team and if needed by a sleep physician for these residual events.

\section{Managing and Counseling Patients on NIV}

\section{Adherence}

$\mathrm{CF}$ is known to have a high treatment burden, and adherence to chronically prescribed therapies is not ideal, with chest physical therapy adherence rates documented between $40-47 \%$ and dietary recommendation adherence rates ranging from 16-20\% ${ }^{82,83}$ Rates of non-adherence to NIV treatment regimens can vary for many reasons and routine clinical assessment for respiratory symptoms, sleep quality, and NIV side effects can allow clinicians to troubleshoot for issues early on in therapy and promote adherence. ${ }^{84,85}$ In addition, taking into account treatment burden as a whole and personalizing treatment plans may help CF patients.

Researchers have attempted to identify patient characteristics that my predispose to lower adherence to NIV. DiFeo et al evaluated patient characteristics such as obesity, race, gender, presence of developmental delay/hyperactivity, parental factors, and PAP-related factors such as pressure, nasal symptoms on PAP adherence in children. ${ }^{86}$ Their analysis revealed that maternal education was the greatest predictor of PAP use for mean hours per night for children. ${ }^{86}$ Family and social support is also predictive of success with CPAP adherence, but not as strong as maternal education. ${ }^{86}$ It is reasonable to assume that family and social support would also predict success in adults, and telemonitoring in the future may also help with adherence in adults. ${ }^{80}$

The type of PAP device used does not affect adherence, although mask type may be a determining factor with a lower compliance noted for full-face masks compared to nasal masks. ${ }^{87}$ Majority of the studies that address specific barriers to adherence in children have focused on the concerns of the patients' family alone. ${ }^{88}$ Simon and colleagues developed a 31-item psychometric questionnaire (ABCQ) to evaluate both child and family barriers to CPAP adherence ${ }^{89}$ In adults with low adherence, it is suggested that clinicians first determine whether the patient has the appropriate mask interface for their facial size, assess for claustrophobia, check for leaks, and ask about adverse events such as dry mouth and aerophagia ${ }^{90}$. Switching mask size, increasing heated humidification, using oral moisturizer rinses, and changing the settings are all possible measures that can be taken to improve adherence. ${ }^{90}$

\section{Maintaining NIV}

Bacterial contamination of home nebulizers of people with CF has been documented, and infection control guidelines for $\mathrm{CF}$ state that durable home nebulizers should be cleaned, disinfected, and air dried after each treatment ${ }^{91}$. Heat or cold disinfectant methods can be followed, as permitted by the manufacturer ${ }^{91}$. Distilled water is not recommended for cleaning of equipment as contamination with B. cepacia can occur during manufacturing ${ }^{91}$. The guidelines do not specifically address NIV, but it is reasonable to assume that following manufacturer guidelines is prudent.

Proper cleaning of NIV-related equipment important in maintenance of equipment as well as preventing infection in users. Daily cleaning of mask can be done with mild detergent and warm water, mask cleaning wipes or spray mask cleaner. ${ }^{92}$ The humidifier chamber needs to be emptied and refilled daily with distilled water. The remainder of the supplies such as headgear, tubing and reusable sponge filter can also 
be cleaned weekly using mild soap and warm water. ${ }^{92}$ Although manufacturer guidelines for NIV may include some suggestions regarding vinegar, vinegar is not recommended in $\mathrm{CF}$ as it has inadequate coverage against S. aureus and other potential CF pathogens ${ }^{91}$. Other commercial disinfecting methods include UV light devices like Lumin and Paptizer, and Ozone devices like Sleep 8, Virtu clean, Zoey and So Clean. [www.thoracic.org] However, none of these devices are FDA approved and manufacturer's warranty excludes damages caused by these devices. ${ }^{93}$

\section{Counseling}

Education on disease progress and the need for medical equipment have shown promise as a strategy for improving patient adherence. ${ }^{94}$ It is important to review the process of obtaining NIV, the benefits, contraindications, what to expect during setup, equipment maintenance, cleaning, supply replacement schedule, and adherence or usage requirements. It is also important to counsel patients on when to call the clinical team versus the durable medical equipment company. In patients with more severe disease, it may be important to discuss the incorporation of NIV into their routines, such as medication, feeding and airway clearance therapy schedules. In addition, the optimal time to start NIV should be a co-decision between the provider and the patient as early usage pattern does establish overall adherence pattern. ${ }^{70,71}$

\section{Conclusion}

Noninvasive ventilation (NIV) use was initially reported in cystic fibrosis (CF) in 1991 as a bridge to lung transplantation, and evidence for use in chronic respiratory failure in CF outside of lung transplantation continues to grow. ${ }^{1-3}$ NIV can increase tidal volume, reduce respiratory rate, and reduce respiratory muscle load both while it is being used and also continually in patients using NIV intermittently. ${ }^{12}$ In addition, NIV can improve gas exchange, quality of sleep, augment airway clearance, and allow for improved exercise tolerance. $^{12}$

It is important for CF providers to know when NIV should be initiated in CF patients, what device and settings to choose in initial prescribing, and what to monitor in patients on this modality. In addition, non-sleep boarded CF providers may benefit from understanding the basics of reviewing a PAP download and consulting with a sleep physician when indicated, especially when the expected benefit is not readily apparent.

Future studies are needed to investigate even earlier intervention with NIV in CF considering its salutary effects in preserving lung function. The entire CF team should be utilized, especially respiratory therapists, to help counsel patients on the importance of adherence, the proper methods of cleaning, and how to fit this therapy into their individual care plan. This review can serve as a resource for CF providers in recognizing hypercarbic respiratory failure, recognizing the impact of NIV, and potentially for initiation of NIV.Acknowledgements The authors thank Dr. Rose Franco MD for her collaboration. The authors also thank the Cystic Fibrosis Foundation for the grant support of the Rutgers-Robert Wood Johnson Medical School pediatric and adult Cystic Fibrosis programs (CC 154).

\section{References}

(1) Hodson, M. E.; Madden, B. P.; Steven, M. H.; Tsang, V. T.; Yacoub, M. H. Non-invasive mechanical ventilation for cystic fibrosis patients-a potential bridge to transplantation. Eur Respir J1991 , 4, 524-527.

(2) Hind, M.; Polkey, M. I.; Simonds, A. K. AJRCCM: 100-Year Anniversary. Homeward Bound: A Centenary of Home Mechanical Ventilation.Am J Respir Crit Care Med 2017 , 195 , 1140-1149.

(3) Bright-Thomas, R. J.; Johnson, S. C. What is the role of noninvasive ventilation in cystic fibrosis? Curr Opin Pulm Med 2014 ,20, 618-622.

(4) Archangelidi, O.; Carr, S. B.; Simmonds, N. J.; Bilton, D.; Banya, W.; Cullinan, P.; EpiNet, C. F. Non-invasive ventilation and clinical outcomes in cystic fibrosis: Findings from the UK CF registry. $J$ Cyst Fibros 2019, $18,665-670$. 
(5) Madden, B. P.; Kariyawasam, H.; Siddiqi, A. J.; Machin, A.; Pryor, J. A.; Hodson, M. E. Noninvasive ventilation in cystic fibrosis patients with acute or chronic respiratory failure. Eur Respir J2002, 19 , 310-313.

(6) Gozal, D. Nocturnal ventilatory support in patients with cystic fibrosis: comparison with supplemental oxygen. Eur Respir J1997 , 10 , 1999-2003.

(7) Milross, M. A.; Piper, A. J.; Norman, M.; Becker, H. F.; Willson, G. N.; Grunstein, R. R.; Sullivan, C. E.; Bye, P. T. Low-flow oxygen and bilevel ventilatory support: effects on ventilation during sleep in cystic fibrosis. Am J Respir Crit Care Med 2001 ,163 , 129-134.

(8) Leger, P.; Bedicam, J. M.; Cornette, A.; Reybet-Degat, O.; Langevin, B.; Polu, J. M.; Jeannin, L.; Robert, D. Nasal intermittent positive pressure ventilation. Long-term follow-up in patients with severe chronic respiratory insufficiency. Chest 1994,105, 100-105.

(9) Milross, M. A.; Piper, A. J.; Dwyer, T. J.; Wong, K.; Bell, S. C.; Bye, P. T. P.; Non-Invasive Ventilation in Cystic Fibrosis Study, G. Non-invasive ventilation versus oxygen therapy in cystic fibrosis: A 12-month randomized trial. Respirology 2019 , 24, 1191-1197.

(10) Franco R, G. J., Sharwani S, Vistocky A. CF Center Capacity to Asses and Treat Sleep Disorders: A National CF Survey. Pediatric Pulmonology 2018, 53 , 5445.

(11) Francis, P. W.; Muller, N. L.; Gurwitz, D.; Milligan, D. W.; Levison, H.; Bryan, A. C. Hemoglobin desaturation: its occurrence during sleep in patients with cystic fibrosis. Am J Dis Child1980 , 134 , 734-740.

(12) Hart, N.; Polkey, M. I.; Clement, A.; Boule, M.; Moxham, J.; Lofaso, F.; Fauroux, B. Changes in pulmonary mechanics with increasing disease severity in children and young adults with cystic fibrosis. $A m$ J Respir Crit Care Med 2002, 166 , 61-66.

(13) Douglas, N. J.; White, D. P.; Weil, J. V.; Pickett, C. K.; Zwillich, C. W. Hypercapnic ventilatory response in sleeping adults.Am Rev Respir Dis 1982, 126 , 758-762.

(14) Johnson, M. W.; Remmers, J. E. Accessory muscle activity during sleep in chronic obstructive pulmonary disease. J Appl Physiol Respir Environ Exerc Physiol 1984 , 57 , 1011-1017.

(15) Jubran, A.; Tobin, M. J. Pathophysiologic basis of acute respiratory distress in patients who fail a trial of weaning from mechanical ventilation. Am J Respir Crit Care Med 1997 ,155 , 906-915.

(16) Piper, A. J.; Parker, S.; Torzillo, P. J.; Sullivan, C. E.; Bye, P. T. Nocturnal nasal IPPV stabilizes patients with cystic fibrosis and hypercapnic respiratory failure. Chest 1992, 102, 846-850.

(17) Serra, A.; Polese, G.; Braggion, C.; Rossi, A. Non-invasive proportional assist and pressure support ventilation in patients with cystic fibrosis and chronic respiratory failure. Thorax 2002, 57, 50-54.

(18) Taylor-Cousar, J. L. Hypoventilation in cystic fibrosis.Semin Respir Crit Care Med 2009 , 30 , 293-302.

(19) Fauroux, B. Noninvasive ventilation in cystic fibrosis.Expert Rev Respir Med 2010 , 4 , 39-46.

(20) Young, A. C.; Wilson, J. W.; Kotsimbos, T. C.; Naughton, M. T. Randomised placebo controlled trial of non-invasive ventilation for hypercapnia in cystic fibrosis. Thorax 2008 , 63 , 72-77.

(21) Fauroux, B.; Le Roux, E.; Ravilly, S.; Bellis, G.; Clement, A. Long-term noninvasive ventilation in patients with cystic fibrosis.Respiration 2008, 76 , 168-174.

(22) Flight, W. G.; Shaw, J.; Johnson, S.; Webb, A. K.; Jones, A. M.; Bentley, A. M.; Bright-Thomas, R. J. Long-term non-invasive ventilation in cystic fibrosis - experience over two decades. J Cyst Fibros $\mathbf{2 0 1 2}$, $11,187-192$. 
(23) Ballard, R. D.; Sutarik, J. M.; Clover, C. W.; Suh, B. Y. Effects of non-REM sleep on ventilation and respiratory mechanics in adults with cystic fibrosis. Am J Respir Crit Care Med 1996 ,153 , 266-271.

(24) Holland, A. E.; Denehy, L.; Ntoumenopoulos, G.; Naughton, M. T.; Wilson, J. W. Non-invasive ventilation assists chest physiotherapy in adults with acute exacerbations of cystic fibrosis. Thorax $\mathbf{2 0 0 3}$, 58 , 880-884.

(25) Bott, J.; Blumenthal, S.; Buxton, M.; Ellum, S.; Falconer, C.; Garrod, R.; Harvey, A.; Hughes, T.; Lincoln, M.; Mikelsons, C.; Potter, C.; Pryor, J.; Rimington, L.; Sinfield, F.; Thompson, C.; Vaughn, P.; White, J.; British Thoracic Society Physiotherapy Guideline Development, G. Guidelines for the physiotherapy management of the adult, medical, spontaneously breathing patient. Thorax 2009, 64 Suppl 1, i1-51.

(26) Rodriguez Hortal, M. C.; Nygren-Bonnier, M.; Hjelte, L. Non-invasive Ventilation as Airway Clearance Technique in Cystic Fibrosis. Physiother Res Int 2017, 22 .

(27) Placidi, G.; Cornacchia, M.; Polese, G.; Zanolla, L.; Assael, B. M.; Braggion, C. Chest physiotherapy with positive airway pressure: a pilot study of short-term effects on sputum clearance in patients with cystic fibrosis and severe airway obstruction. Respir Care 2006 , 51, 1145-1153.

(28) Stanford, G.; Parrott, H.; Bilton, D.; Agent, P. Positive pressure-analysing the effect of the addition of non-invasive ventilation (NIV) to home airway clearance techniques (ACT) in adult cystic fibrosis (CF) patients. Physiother Theory Pract2015 , 31 , 270-274.

(29) Carron, M.; Freo, U.; BaHammam, A. S.; Dellweg, D.; Guarracino, F.; Cosentini, R.; Feltracco, P.; Vianello, A.; Ori, C.; Esquinas, A. Complications of non-invasive ventilation techniques: a comprehensive qualitative review of randomized trials. Br J Anaesth2013, 110 , 896-914.

(30) Organized jointly by the American Thoracic Society, t. E. R. S. t. E. S. o. I. C. M.; the Societe de Reanimation de Langue, F.; approved by Ats Board of Directors, D. International Consensus Conferences in Intensive Care Medicine: noninvasive positive pressure ventilation in acute Respiratory failure. Am J Respir Crit Care Med 2001, 163 , 283-291.

(31) Kohlenberg, A.; Schwab, F.; Behnke, M.; Geffers, C.; Gastmeier, P. Pneumonia associated with invasive and noninvasive ventilation: an analysis of the German nosocomial infection surveillance system database. Intensive Care Med 2010, 36 , 971-978.

(32) Gay, P. C. Complications of noninvasive ventilation in acute care.Respir Care 2009 , 54 , 246-257; discussion 257-248.

(33) Bongiovanni, A.; Manti, S.; Parisi, G. F.; Papale, M.; Mule, E.; Rotolo, N.; Leonardi, S. Focus on gastroesophageal reflux disease in patients with cystic fibrosis. World J Gastroenterol2020 , 26 , 6322-6334.

(34) Zeybel, G. L.; Pearson, J. P.; Krishnan, A.; Bourke, S. J.; Doe, S.; Anderson, A.; Faruqi, S.; Morice, A. H.; Jones, R.; McDonnell, M.; Zeybel, M.; Dettmar, P. W.; Brodlie, M.; Ward, C. Ivacaftor and symptoms of extra-oesophageal reflux in patients with cystic fibrosis and G551D mutation. J Cyst Fibros 2017 , 16 , 124-131.

(35) De Keulenaer, B. L.; De Backer, A.; Schepens, D. R.; Daelemans, R.; Wilmer, A.; Malbrain, M. L. Abdominal compartment syndrome related to noninvasive ventilation. Intensive Care Med 2003 ,29, 1177-1181.

(36) Luria, O.; Reshef, L.; Barnea, O. Analysis of non-invasive ventilation effects on gastric inflation using a non-linear mathematical model. Resuscitation 2006 , 71, 358-364.

(37) Haworth, C. S.; Dodd, M. E.; Atkins, M.; Woodcock, A. A.; Webb, A. K. Pneumothorax in adults with cystic fibrosis dependent on nasal intermittent positive pressure ventilation (NIPPV): a management dilemma. Thorax 2000 , 55, 620-622. 
(38) Guarracino, F.; Ambrosino, N. Non invasive ventilation in cardio-surgical patients. Minerva Anestesiol $2011,77,734-741$.

(39) Kapnadak, S. G.; Dimango, E.; Hadjiliadis, D.; Hempstead, S. E.; Tallarico, E.; Pilewski, J. M.; Faro, A.; Albright, J.; Benden, C.; Blair, S.; Dellon, E. P.; Gochenour, D.; Michelson, P.; Moshiree, B.; Neuringer, I.; Riedy, C.; Schindler, T.; Singer, L. G.; Young, D.; Vignola, L.; Zukosky, J.; Simon, R. H. Cystic Fibrosis Foundation consensus guidelines for the care of individuals with advanced cystic fibrosis lung disease. $J$ Cyst Fibros 2020 , 19 , 344-354.

(40) Dwyer, T. J.; Robbins, L.; Kelly, P.; Piper, A. J.; Bell, S. C.; Bye, P. T. Non-invasive ventilation used as an adjunct to airway clearance treatments improves lung function during an acute exacerbation of cystic fibrosis: a randomised trial. $J$ Physiother 2015, 61, 142-147.

(41) Cadiergue, V.; Philit, F.; Langevin, B.; Durieu, I.; Bertocchi, M.; Guerin, C.; Robert, D. [Outcome of adult patients with cystic fibrosis admitted to intensive care with respiratory failure: the role of non-invasive ventilation]. Rev Mal Respir 2002 ,19 , 425-430.

(42) Brochard, L.; Mancebo, J.; Wysocki, M.; Lofaso, F.; Conti, G.; Rauss, A.; Simonneau, G.; Benito, S.; Gasparetto, A.; Lemaire, F.; et al. Noninvasive ventilation for acute exacerbations of chronic obstructive pulmonary disease. N Engl J Med 1995 ,333 , 817-822.

(43) Fauroux, B.; Burgel, P. R.; Boelle, P. Y.; Cracowski, C.; Murris-Espin, M.; Nove-Josserand, R.; Stremler, N.; Derlich, L.; Giovanetti, P.; Clement, A.; Chronic Respiratory Insufficiency Group of the French National Cystic Fibrosis, F. Practice of noninvasive ventilation for cystic fibrosis: a nationwide survey in France.Respir Care 2008 , 53 , 1482-1489.

(44) Waterhouse, D. F.; McLaughlin, A. M.; Gallagher, C. G. Time course and recovery of arterial blood gases during exacerbations in adults with Cystic Fibrosis. J Cyst Fibros 2009 , 8 , 9-13.

(45) Kerem, E.; Reisman, J.; Corey, M.; Canny, G. J.; Levison, H. Prediction of mortality in patients with cystic fibrosis. N Engl J Med 1992 , 326 , 1187-1191.

(46) Hill, A. T.; Edenborough, F. P.; Cayton, R. M.; Stableforth, D. E. Long-term nasal intermittent positive pressure ventilation in patients with cystic fibrosis and hypercapnic respiratory failure (1991-1996).Respir Med 1998 , 92 , 523-526.

(47) Annane, D.; Orlikowski, D.; Chevret, S. Nocturnal mechanical ventilation for chronic hypoventilation in patients with neuromuscular and chest wall disorders. Cochrane Database Syst Rev2014 , CD001941.

(48) Bourke, S. C.; Tomlinson, M.; Williams, T. L.; Bullock, R. E.; Shaw, P. J.; Gibson, G. J. Effects of non-invasive ventilation on survival and quality of life in patients with amyotrophic lateral sclerosis: a randomised controlled trial. Lancet Neurol2006 , 5 , 140-147.

(49) Simonds, A. K. Home Mechanical Ventilation: An Overview. Ann Am Thorac Soc 2016 , 13 , 20352044.

(50) Moran, F.; Bradley, J. M.; Piper, A. J. Non-invasive ventilation for cystic fibrosis. Cochrane Database Syst Rev 2017,2, CD002769.

(51) Sullivan, C. E.; Issa, F. G.; Berthon-Jones, M.; Eves, L. Reversal of obstructive sleep apnoea by continuous positive airway pressure applied through the nares. Lancet 1981, 1 , 862-865.

(52) Iftikhar, I. H.; Bittencourt, L.; Youngstedt, S. D.; Ayas, N.; Cistulli, P.; Schwab, R.; Durkin, M. W.; Magalang, U. J. Comparative efficacy of CPAP, MADs, exercise-training, and dietary weight loss for sleep apnea: a network meta-analysis. Sleep Med 2017,30 , 7-14.

(53) Patil, S. P.; Ayappa, I. A.; Caples, S. M.; Kimoff, R. J.; Patel, S. R.; Harrod, C. G. Treatment of Adult Obstructive Sleep Apnea With Positive Airway Pressure: An American Academy of Sleep Medicine Systematic Review, Meta-Analysis, and GRADE Assessment. J Clin Sleep Med 2019 , 15 , 301-334. 
(54) Morgenthaler, T. I.; Gay, P. C.; Gordon, N.; Brown, L. K. Adaptive servoventilation versus noninvasive positive pressure ventilation for central, mixed, and complex sleep apnea syndromes. Sleep $\mathbf{2 0 0 7}$, 30 , 468-475.

(55) American Academy of Sleep Medicine. International Classification of Sleep Disorders, 3rd Edition, 2014.

(56) Selim, B.; Ramar, K. Sleep-Related Breathing Disorders: When CPAP Is Not Enough. Neurotherapeutics 2020 .

(57) Aurora, R. N.; Chowdhuri, S.; Ramar, K.; Bista, S. R.; Casey, K. R.; Lamm, C. I.; Kristo, D. A.; Mallea, J. M.; Rowley, J. A.; Zak, R. S.; Tracy, S. L. The treatment of central sleep apnea syndromes in adults: practice parameters with an evidence-based literature review and meta-analyses. Sleep 2012 , 35 , $17-40$.

(58) Pinto, A.; de Carvalho, M.; Evangelista, T.; Lopes, A.; Sales-Luis, L. Nocturnal pulse oximetry: a new approach to establish the appropriate time for non-invasive ventilation in ALS patients. Amyotroph Lateral Scler Other Motor Neuron Disord 2003 , 4 , 31-35.

(59) Pinto, A. C.; Evangelista, T.; Carvalho, M.; Alves, M. A.; Sales Luis, M. L. Respiratory assistance with a non-invasive ventilator (Bipap) in MND/ALS patients: survival rates in a controlled trial.J Neurol Sci 1995, 129 Suppl, 19-26.

(60) Aboussouan, L. S.; Khan, S. U.; Meeker, D. P.; Stelmach, K.; Mitsumoto, H. Effect of noninvasive positive-pressure ventilation on survival in amyotrophic lateral sclerosis. Ann Intern Med1997 , 127, 450-453.

(61) Gruis, K. L.; Brown, D. L.; Schoennemann, A.; Zebarah, V. A.; Feldman, E. L. Predictors of noninvasive ventilation tolerance in patients with amyotrophic lateral sclerosis. Muscle Nerve2005 , 32 , 808-811.

(62) Lyall, R. A.; Donaldson, N.; Fleming, T.; Wood, C.; Newsom-Davis, I.; Polkey, M. I.; Leigh, P. N.; Moxham, J. A prospective study of quality of life in ALS patients treated with noninvasive ventilation. Neurology 2001, 57, 153-156.

(63) Butz, M.; Wollinsky, K. H.; Wiedemuth-Catrinescu, U.; Sperfeld, A.; Winter, S.; Mehrkens, H. H.; Ludolph, A. C.; Schreiber, H. Longitudinal effects of noninvasive positive-pressure ventilation in patients with amyotrophic lateral sclerosis. Am J Phys Med Rehabil2003 , 82 , 597-604.

(64) Jackson, C. E.; Rosenfeld, J.; Moore, D. H.; Bryan, W. W.; Barohn, R. J.; Wrench, M.; Myers, D.; Heberlin, L.; King, R.; Smith, J.; Gelinas, D.; Miller, R. G. A preliminary evaluation of a prospective study of pulmonary function studies and symptoms of hypoventilation in ALS/MND patients. J Neurol Sci 2001 , 191, 75-78.

(65) Miller, R. G.; Jackson, C. E.; Kasarskis, E. J.; England, J. D.; Forshew, D.; Johnston, W.; Kalra, S.; Katz, J. S.; Mitsumoto, H.; Rosenfeld, J.; Shoesmith, C.; Strong, M. J.; Woolley, S. C.; Quality Standards Subcommittee of the American Academy of, N. Practice parameter update: the care of the patient with amyotrophic lateral sclerosis: drug, nutritional, and respiratory therapies (an evidence-based review): report of the Quality Standards Subcommittee of the American Academy of Neurology. Neurology 2009 , 73 , 12181226 .

(66) Hull, J.; Aniapravan, R.; Chan, E.; Chatwin, M.; Forton, J.; Gallagher, J.; Gibson, N.; Gordon, J.; Hughes, I.; McCulloch, R.; Russell, R. R.; Simonds, A. British Thoracic Society guideline for respiratory management of children with neuromuscular weakness. Thorax 2012, 67 Suppl 1, i1-40.

(67) Wang, C. H.; Finkel, R. S.; Bertini, E. S.; Schroth, M.; Simonds, A.; Wong, B.; Aloysius, A.; Morrison, L.; Main, M.; Crawford, T. O.; Trela, A.; Participants of the International Conference on, S. M. A. S. o. C. Consensus statement for standard of care in spinal muscular atrophy. J Child Neurol 2007, 22 , 1027-1049. 
(68) Finder, J. D.; Birnkrant, D.; Carl, J.; Farber, H. J.; Gozal, D.; Iannaccone, S. T.; Kovesi, T.; Kravitz, R. M.; Panitch, H.; Schramm, C.; Schroth, M.; Sharma, G.; Sievers, L.; Silvestri, J. M.; Sterni, L.; American Thoracic, S. Respiratory care of the patient with Duchenne muscular dystrophy: ATS consensus statement. Am J Respir Crit Care Med 2004 , 170 , 456-465.

(69) Hess, D. R. Noninvasive Ventilation for Neuromuscular Disease.Clin Chest Med 2018 , 39 , 437-447.

(70) Weaver, T. E.; Kribbs, N. B.; Pack, A. I.; Kline, L. R.; Chugh, D. K.; Maislin, G.; Smith, P. L.; Schwartz, A. R.; Schubert, N. M.; Gillen, K. A.; Dinges, D. F. Night-to-night variability in CPAP use over the first three months of treatment. Sleep 1997, 20, 278-283.

(71) Chai-Coetzer, C. L.; Luo, Y. M.; Antic, N. A.; Zhang, X. L.; Chen, B. Y.; He, Q. Y.; Heeley, E.; Huang, S. G.; Anderson, C.; Zhong, N. S.; McEvoy, R. D. Predictors of long-term adherence to continuous positive airway pressure therapy in patients with obstructive sleep apnea and cardiovascular disease in the SAVE study. Sleep 2013 ,36 , 1929-1937.

(72) Genta, P. R.; Kaminska, M.; Edwards, B. A.; Ebben, M. R.; Krieger, A. C.; Tamisier, R.; Ye, L.; Weaver, T. E.; Vanderveken, O. M.; Lorenzi-Filho, G.; DeYoung, P.; Hevener, W.; Strollo, P. The Importance of Mask Selection on Continuous Positive Airway Pressure Outcomes for Obstructive Sleep Apnea. An Official American Thoracic Society Workshop Report. Ann Am Thorac Soc 2020 , 17, 1177-1185.

(73) Bachour, A.; Vitikainen, P.; Maasilta, P. Rates of initial acceptance of PAP masks and outcomes of mask switching. Sleep Breath 2016 , 20, 733-738.

(74) Clinical Indications for the Use of Respiratory Assist Device (RAD) Therapy: CMS.gov, 2018.

(75) Fauroux, B.; Louis, B.; Hart, N.; Essouri, S.; Leroux, K.; Clement, A.; Polkey, M. I.; Lofaso, F. The effect of back-up rate during non-invasive ventilation in young patients with cystic fibrosis. Intensive Care Med 2004, 30, 673-681.

(76) Zhang, X.; Yang, P.; Guo, C.; Li, S.; Zhang, Y. Effects of volume-assured pressure support noninvasive ventilation in stable COPD with chronic respiratory failure: Meta-analysis and literature review. Heart Lung 2020, $49,287-295$.

(77) Harte, B. J.; Wesorick, D.; Odden, A. Chronic Obstructive Pulmonary Disease: Inpatient Management. Hosp Med Clin 2013 ,2, e169-e191.

(78) Macrea, M.; Oczkowski, S.; Rochwerg, B.; Branson, R. D.; Celli, B.; Coleman, J. M., 3rd; Hess, D. R.; Knight, S. L.; Ohar, J. A.; Orr, J. E.; Piper, A. J.; Punjabi, N. M.; Rahangdale, S.; Wijkstra, P. J.; YimYeh, S.; Drummond, M. B.; Owens, R. L. Long-Term Noninvasive Ventilation in Chronic Stable Hypercapnic Chronic Obstructive Pulmonary Disease. An Official American Thoracic Society Clinical Practice Guideline. Am J Respir Crit Care Med 2020, 202, e74-e87.

(79) Diaz, O.; Iglesia, R.; Ferrer, M.; Zavala, E.; Santos, C.; Wagner, P. D.; Roca, J.; Rodriguez-Roisin, R. Effects of noninvasive ventilation on pulmonary gas exchange and hemodynamics during acute hypercapnic exacerbations of chronic obstructive pulmonary disease. Am J Respir Crit Care Med 1997, 156 , 1840-1845.

(80) Arnal, J. M.; Texereau, J.; Garnero, A. Practical Insight to Monitor Home NIV in COPD Patients. COPD 2017, $14,401-410$.

(81) Georges, M.; Rabec, C.; Monin, E.; Aho, S.; Beltramo, G.; Janssens, J. P.; Bonniaud, P. Monitoring of noninvasive ventilation: comparative analysis of different strategies. Respir Res 2020 ,21 , 324 .

(82) Quittner, A. L.; Modi, A. C.; Lemanek, K. L.; Ievers-Landis, C. E.; Rapoff, M. A. Evidence-based assessment of adherence to medical treatments in pediatric psychology. J Pediatr Psychol2008 , 33 , 916936; discussion 937-918.

(83) Anthony, H.; Paxton, S.; Bines, J.; Phelan, P. Psychosocial predictors of adherence to nutritional 
recommendations and growth outcomes in children with cystic fibrosis. J Psychosom Res1999 , 47, 623634.

(84) Borel, J. C.; Pepin, J. L.; Pison, C.; Vesin, A.; Gonzalez-Bermejo, J.; Court-Fortune, I.; Timsit, J. F. Long-term adherence with non-invasive ventilation improves prognosis in obese COPD patients.Respirology 2014, $19,857-865$.

(85) Dupuis-Lozeron, E.; Gex, G.; Pasquina, P.; Bridevaux, P. O.; Borel, J. C.; Soccal, P. M.; Windisch, W.; Pepin, J. L.; Janssens, J. P.; Adler, D. Development and validation of a simple tool for the assessment of home noninvasive ventilation: the $\mathrm{S}(3)$-NIV questionnaire. Eur Respir $J \mathbf{2 0 1 8}$, 52 .

(86) DiFeo, N.; Meltzer, L. J.; Beck, S. E.; Karamessinis, L. R.; Cornaglia, M. A.; Traylor, J.; Samuel, J.; Gallagher, P. R.; Radcliffe, J.; Beris, H.; Menello, M. K.; Marcus, C. L. Predictors of positive airway pressure therapy adherence in children: a prospective study.J Clin Sleep Med 2012 , 8 , 279-286.

(87) O'Donnell, A. R.; Bjornson, C. L.; Bohn, S. G.; Kirk, V. G. Compliance rates in children using noninvasive continuous positive airway pressure. Sleep 2006, 29, 651-658.

(88) DiMatteo, M. R.; Giordani, P. J.; Lepper, H. S.; Croghan, T. W. Patient adherence and medical treatment outcomes: a meta-analysis. Med Care 2002, 40, 794-811.

(89) Simon, S. L.; Duncan, C. L.; Janicke, D. M.; Wagner, M. H. Barriers to treatment of paediatric obstructive sleep apnoea: Development of the adherence barriers to continuous positive airway pressure (CPAP) questionnaire. Sleep Med 2012, 13, 172-177.

(90) Choi, P.; Adam, V.; Zielinski, D. Noninvasive Ventilation Downloads and Monitoring. Sleep Med Clin 2020, $15,569-579$.

(91) Saiman, L.; Siegel, J. D.; LiPuma, J. J.; Brown, R. F.; Bryson, E. A.; Chambers, M. J.; Downer, V. S.; Fliege, J.; Hazle, L. A.; Jain, M.; Marshall, B. C.; O’Malley, C.; Pattee, S. R.; Potter-Bynoe, G.; Reid, S.; Robinson, K. A.; Sabadosa, K. A.; Schmidt, H. J.; Tullis, E.; Webber, J.; Weber, D. J.; Cystic Fibrous, F.; Society for Healthcare Epidemiology of, A. Infection prevention and control guideline for cystic fibrosis: 2013 update. Infect Control Hosp Epidemiol2014, 35 Suppl 1, S1-S67.

(92) Schotland, H. The Care and Cleaning of Your PAP Device. Am J Respir Crit Care Med 2020 , 201 , P23-P24.

(93) FDA Reminds Patients that Devices Claiming to Clean, Disinfect or Sanitize CPAP Machines Using Ozone Gas or UV Light Have Not Been FDA Authorized, 2020.

(94) Strickland, S. L. The Patient Experience During Noninvasive Respiratory Support. Respir Care 2019 ,64, 689-700.

(95) Fauroux, B.; Pigeot, J.; Polkey, M. I.; Isabey, D.; Clement, A.; Lofaso, F. In vivo physiologic comparison of two ventilators used for domiciliary ventilation in children with cystic fibrosis. Crit Care Med 2001, 29 , 2097-2105. 


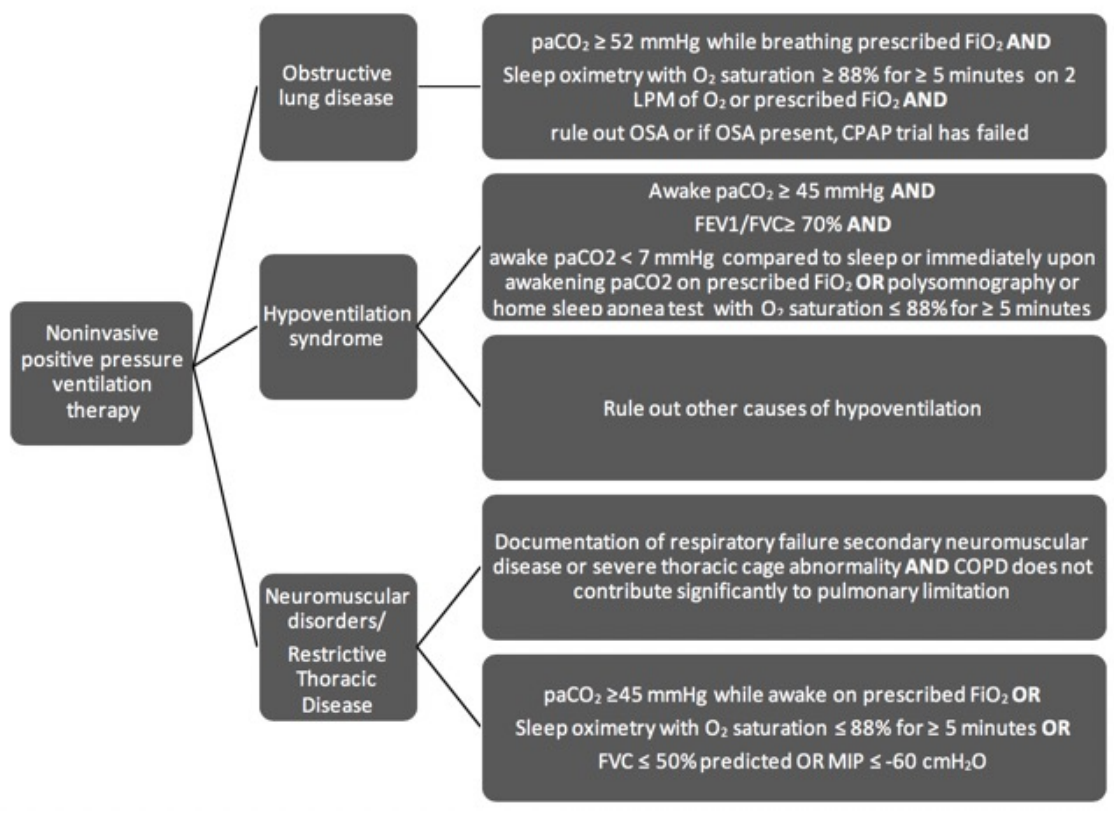

\section{Hosted file}

Table 1.docx available at https://authorea.com/users/323531/articles/526947-an-overview-ofnoninvasive-ventilation-in-cystic-fibrosis

\section{Hosted file}

Table 2.docx available at https://authorea.com/users/323531/articles/526947-an-overview-ofnoninvasive-ventilation-in-cystic-fibrosis

\section{Hosted file}

Table 3.docx available at https://authorea.com/users/323531/articles/526947-an-overview-ofnoninvasive-ventilation-in-cystic-fibrosis 